\title{
Research Article \\ SCREENING AND CHARACTERIZATION OF STRESS TOLERANT RHIZOBIA FROM DIFFERENT SOILS OF TELANGANA
}

\author{
DAMODARA CHARI K. ${ }^{*}$, SUBHASH REDDY R. ${ }^{2}$, TRIVENI S. ${ }^{3}$, TRIMURTULU N. ${ }^{4}$, DURGA RANI V. ${ }^{5}$ AND SREEDHAR M. ${ }^{6}$ \\ 1,2,3Department of Agricultural Microbiology \& Bioenergy, College of Agriculture, Professor Jayashankar Telangana State Agricultural University, Rajendranagar, \\ Hyderabad, 500030, Telangana, India \\ ${ }^{4}$ Biofertilizer Production Laboratory, Agricultural Research Station, Amaravathi, Guntur, 522020, Andhra Pradesh, India \\ ${ }^{5}$ Department of Molecular Biology \& Biotechnology, Institute of Biotechnology, Professor Jayashankar Telangana State Agricultural University, Rajendranagar, Hyderabad, \\ 500030, Telangana, India \\ ${ }^{6}$ Quality Control Laboratory, Professor Jayashankar Telangana State Agricultural University, Rajendranagar, Hyderabad, 500030, Telangana, India \\ *Corresponding Author: Email-charigorukallu@gmail.com
}

Received: March 05, 2018; Revised: March 09, 2018; Accepted: March 10, 2018; Published: March 30, 2018

\begin{abstract}
Present in vitro experiment was carried out to identify plant growth promoting rhizobial isolates for abiotic stress tolerance. Rhizospheric soils from normal, salt affected, drought affected were collected from different places of Telangana state. From all soil samples, twenty one rhizobial isolates were collected. Among the twenty one isolates, eleven isolates were showed different plant growth promoting properties. The results of different in vitro abiotic stress tolerance of isolates reveals that, only one isolate showed tolerance to temperature from $20^{\circ} \mathrm{C}-50^{\circ} \mathrm{C}$ (YR-21), three isolates were showed tolerance to temperature from $20^{\circ} \mathrm{C}-45^{\circ} \mathrm{C}(\mathrm{RR}-1, \mathrm{GR}-5$, GNR-8), one isolate was showed tolerance to temperature from $30^{\circ} \mathrm{C}-45^{\circ} \mathrm{C}$ (MR-11), only one isolate were showed tolerance to temperature from $30^{\circ} \mathrm{C}-40^{\circ} \mathrm{C}(\mathrm{ASR}-$ 17). Two isolates showed tolerance to water potential from $-0.05 \mathrm{Mpa}$ to- $0.15 \mathrm{Mpa}$ (RR-1, RR-3), three isolates were showed tolerance to water potential from - 0.05 Mpa to $-0.30 \mathrm{Mpa}$ (GNR-8, ASR-19, YR-21), only one isolate showed tolerance to water potential at - $0.05 \mathrm{Mpa}$ (GNR-7).
\end{abstract}

Keywords- Rhizobium, PGPR, temperature, drought tolerance.

Citation: Damodara Chari K., et al., (2018) Screening and Characterization of Stress Tolerant Rhizobia from Different Soils of Telangana. International Journal of Microbiology Research, ISSN: 0975-5276 \& E-ISSN: 0975-9174, Volume 10, Issue 3, pp.-1038-1042. DOl: http://dx.doi.org/10.9735/0975-5276.10.3.1038-1042

Copyright: Copyright@2018 Damodara Chari K., et al., This is an open-access article distributed under the terms of the Creative Commons Attribution License, which permits unrestricted use, distribution and reproduction in any medium, provided the original author and source are credited.

\section{Introduction}

The rhizobia-legumes symbioses can benefit not only the host crop, but it may also have positive effects for subsequent crops [1]. Furthermore, rhizobia may also act as non-symbiotic PGPB as in the case of economically important nonlegume crops such as rice or wheat, which are the best studied examples that benefit from rhizobia as endophytes [2], [3]. Values estimated for various legume crops and pasture species are often impressive, commonly falling in the range of 200 to $300 \mathrm{~kg}$ of N ha ${ }^{-1}$ year-1 [4]. Yield increases of crops planted after harvesting of legumes are often equivalent to those expected from application of 30 to $80 \mathrm{~kg}$ of fertilizer $\mathrm{N} \mathrm{ha}^{-1}$. A fully functional symbiosis requires successful survival ability of Rhizobium even under adverse environmental conditions.

One of the major problems in rain fed agro-ecosystems is predominance of abiotic stresses like high temperature, salinity and drought where the applied bioinoculants survival and viability is a major issue in Indian conditions. Abiotic and biotic stresses are the limiting factors negatively affecting the crop growth and productivity worldwide. Plants responses to such factors are very complex which manifest in a range of developmental, molecular and physiological modifications that lead to either stress sensitivity or tolerance/resistance [5]. A given stress may also have more than one effect: e.g., salinity may act as a water stress, which affects the photosynthetic rate, or may affect nodule metabolism directly. Populations of Rhizobium and Bradyrhizobium spp., vary in their tolerance to environmental factors; consequently, screening for tolerant strains has been pursued. However, rhizobial populations are known to vary in their tolerance to major environmental factors [6].

The wild (naturally-growing) leguminous plants living in arid and semi arid regions are subject to severe environmental conditions. In addition, desertification causes disturbance of plant-microbe symbioses, which are a critical ecological factor in helping further plant growth in degraded ecosystems. Among several environmental conditions, which are limiting factor such as salinity, temperature extremes and $\mathrm{pH}$ stress are probably the most problematic. A competitive and persistent rhizobial strain is not expected to express its full capacity for nitrogen fixation as the limiting factors (e.g. salinity, unfavourable soil pH, temperature extremes, nutrient deficiency etc.) impose limitations on the vigour of the host legume. Inoculation of stress tolerant strains of rhizobia may enhance the nodulation and nitrogen fixation ability of plants under stress conditions.

Plant growth promoting rhizobacteria can improve plant growth and productivity by several mechanisms. Few strains from genera such as Bacillus, Pseudomonas, Erwinia, Caulobacter, Serratia, Arthrobacter, Micrococcus, Flavobacterium, Chromobacterium, Agrobacterium, Hyphomycrobium, Rhizobium, Bradyrhizobium, Sinorhizobium, Azorhizobium, Mesorhizobium and Allorhizobium are well known PGPR. They aid in improving plant stress tolerance to drought, salinity and metal toxicity. The underlying mechanisms of plant growth promotion by PGPR have been comprehensively described in several articles [7, 8].

Selection of effective, efficient and compatible stress tolerant rhizobial strains could help in ecological rehabilitation of degraded soils and increases soil fertility thereby improving the growth of associated plants of this Telangana region. 


\section{Materials and methods}

\section{Isolation of native rhizobia}

The selection of rhizobial cultures were obtained from different locations, such as normal soils, salt affected drought soils grown legumes root nodules. The rhizobial isolates (R-1 to R-21) [Table-1] were identified based on their morphological, biochemical characters and fixing ability, nodulation capacity. Further these isolates were tested abiotic tolerant efficiency.

Table-1 Number of hizobial isolates obtained from different districts along with their isolate number

\begin{tabular}{|c|l|l|c|}
\hline S. No & \multicolumn{1}{|c|}{ District } & \multicolumn{1}{|c|}{ Rhizobial lsolates number } & $\begin{array}{c}\text { No. of } \\
\text { isolates }\end{array}$ \\
\hline 1 & Rangareddy & $\begin{array}{l}\text { Redgram - 3 isolates (RR1 - RR 3), } \\
\text { Greengram- 2 isolates (GR 4 - GR 5), } \\
\text { Groundnut - 4 isolates (GNR 6- GNR 9) }\end{array}$ & 9 \\
\hline 2. & Mahabubnagar & Redgram -2 isolates (MR 10 - MR 11) & 2 \\
\hline 3 & Wanaparthi & $\begin{array}{l}\text { Redgram- 2 isolates (WR 12- WR 13), } \\
\text { Groundnut -2 isolates (WR 14- WR 15) }\end{array}$ & 4 \\
\hline 4 & Nagarkurnool & Soybean - 1 isolate (NSR 16) & 1 \\
\hline 5 & Adilabad & Soybean-2 isolates (ASR 17 - ASR 19) & 2 \\
\hline 6 & Yadagirigutta & $\begin{array}{l}\text { Redgram- 1 isolate (YR 20), Soybean- 1 } \\
\text { isolate (YR 21) }\end{array}$ & 3 \\
\hline
\end{tabular}

Determination of mineral solubilization, IAA production, antagonistic activity ACC Deaminase activity and EPS production

Phosphate solubilization activity was determined using Pikovskaya's agar medium containing $0.5 \%$ (W/V) $\mathrm{Ca}_{3}\left(\mathrm{PO}_{4}\right)_{2}$ [9], Potassium solubilization determined using Aleksandrov medium containing $0.2 \%$ potassium aluminum silicate [10], Zinc solubilization determined using Tris mineral salt medium containing $0.1 \% \mathrm{ZnO}$ [11], IAA production [12], Exo polysaccharide production at stress induced conditions were checked [13], bacterial utilization of ACC as sole nitrogen source was screened using qualitative assay [14]. Siderophore production was determined by the chrome azurol S plate assay [15], antagonistic activity was verified by following dual culture technique [16].

\section{Screening for abiotic stress tolerance ability of rhizobial isolates Screening of rhizobial isolates for temperature tolerance}

$0.1 \mathrm{ml}$ of bacterial suspension $\left(10^{8}-10^{9}\right.$ cells $\left.\mathrm{ml}^{-1}\right)$ was poured into the vials containing $5 \mathrm{ml} \mathrm{TSB}$ culture medium and culture in incubators at $20^{\circ} \mathrm{C}, 30^{\circ} \mathrm{C}$, $40^{\circ} \mathrm{C}, 45^{\circ} \mathrm{C}$ and $50^{\circ} \mathrm{C}$ in three replicates for each. After $24 \mathrm{hrs}$ of culture, their absorbance was measured at $600 \mathrm{~nm}$.

\section{Screening of rhizobial isolates for drought tolerance}

Yeast mannitol broth with different water potentials $(-0.05,-0.15,-0.30,-0.49$, and $-0.73 \mathrm{MPa}$ ) was prepared by adding appropriate concentrations of polyethylene glycol (PEG 6000) [17]. Log phase grown culture was inoculated in YEM broth supplemented with different concentration of polyethylene glycol (PEG 6000). Osmotic potential of broth media was measured by osmometer. Three replicates of each isolate with each concentration were prepared. Growth was estimated by measuring the optical density values at $600 \mathrm{~nm}$ using a spectrophotometer

\section{Results and Discussion Isolation of rhizobia}

Two or three healthy pink nodules were collected from each plant and surface sterilized by using $0.1 \% \mathrm{HgCl}_{2}$ and $70 \%$ ethanol as described in Material and Methods. The nodules were crushed and streaked on YEMA medium plates containing congo red dye. The colonies from each nodule were purified by streaking 2-3 times on same media. In total twenty one rhizobial isolates were obtained from different districts [Table-1]. These isolates were further purified and maintained on YEMA slants for further studies.

\section{Characterization of rhizobia}

About twenty one isolates showed small to medium, milky translucent, raised, mucoid colonies and formed non-spreading type of colonies. The colony morphology of isolates was examined on YEM agar plates. These pure cultures were checked for purity by streaking on different media like Hofer's alkaline agar, glucose peptone agar agar and lactose agar plates. None of the isolates showed any growth on these media plates. Among twenty one Gram negative Rhizobium bacterial isolates, all the isolates showed positive results for citrate utilization, oxidase test, catalase test. Nineteen isolates were positive for indole production. Nineteen isolates showed positive for methyl red test, thirteen isolates were positive for Voges-praskauer test. While all the isolates utilized mannitol, fifteen isolates utilized sucrose; ten isolates utilized lactose sugar and seventeen isolates utilized glucose sugar.

\section{Plant growth promoting properties}

Out of twenty one isolates, eleven isolates were positive for different plant growth promoting properties in in vitro conditions [Table-2].

\begin{tabular}{|c|c|c|c|c|c|c|c|c|}
\hline Isolates & $\begin{array}{l}\text { P solubilization } \\
\text { (mm) }\end{array}$ & $\begin{array}{c}\text { K Solubilization } \\
(\mathrm{mm})\end{array}$ & $\begin{array}{c}\text { Zn Solubilization } \\
(\mathrm{mm})\end{array}$ & $\begin{array}{l}\text { IAA Production } \\
\left(\mu \mathrm{g} \mathrm{ml} \mathrm{I}^{-1}\right)\end{array}$ & $\begin{array}{c}\text { HCN } \\
\text { Production }\end{array}$ & $\begin{array}{l}\text { Antagonistic } \\
\text { activity (mm) }\end{array}$ & $\begin{array}{c}\text { ACC } \\
\text { deaminase } \\
\text { activity }\end{array}$ & $\begin{array}{c}\text { EPS } \\
\text { production }\end{array}$ \\
\hline RR 1 & $11.66 \pm 1.20$ & $10.33 \pm 0.88$ & $8.33 \pm 0.33$ & $18.70 \pm 0.14$ & - & - & ++ & ++ \\
\hline RR 3 & $4.33 \pm 0.33$ & $7.33 \pm 0.88$ & $6.00 \pm 1.15$ & $4.48 \pm 0.25$ & - & - & - & + \\
\hline GR 5 & $10.33 \pm 0.88$ & $6.00 \pm 1.00$ & $15.00 \pm 1.73$ & $10.21 \pm 0.00$ & - & - & + & + \\
\hline GNR 7 & $2.33 \pm 0.33$ & $14.66 \pm 0.88$ & $14.66 \pm 0.88$ & $6.20 \pm 0.57$ & - & - & - & - \\
\hline GNR 8 & $8.33 \pm 0.88$ & $4.33 \pm 0.88$ & $3.00 \pm 0.57$ & $4.50 \pm 0.25$ & - & - & + & + \\
\hline MR 10 & $13.66 \pm 0.33$ & $13.00 \pm 0.57$ & $10.33 \pm 0.88$ & $10.36 \pm 1.15$ & - & - & - & - \\
\hline MR 11 & $5.33 \pm 0.88$ & $13.00 \pm 1.00$ & $3.33 \pm 0.33$ & $12.48 \pm 0.25$ & - & - & - & - \\
\hline \begin{tabular}{|l|} 
WR 14 \\
\end{tabular} & $6.33 \pm 0.33$ & $2.83 \pm 0.16$ & $13.00 \pm 1.15$ & $5.44 \pm 0.92$ & + & 13 & ++ & ++ \\
\hline \begin{tabular}{|l|} 
ASR 17 \\
\end{tabular} & $7.33 \pm 1.33$ & $3.06 \pm 0.06$ & $3.33 \pm 0.88$ & $1.50 \pm 0.25$ & - & - & + & + \\
\hline ASR 19 & $18.00 \pm 1.15$ & $3.33 \pm 0.88$ & $2.66 \pm 0.33$ & $9.55 \pm 1.44$ & - & - & - & - \\
\hline \begin{tabular}{|l|} 
YR 21 \\
\end{tabular} & $3.33 \pm 0.88$ & $4.00 \pm 1.00$ & $6.33 \pm 0.33$ & $8.50 \pm 0.25$ & - & - & - & - \\
\hline $\operatorname{SE}(m) \pm$ & 0.859 & 0.812 & 0.893 & 0.670 & & & & \\
\hline CD & 2.535 & 2.397 & 2.637 & 1.979 & & & & \\
\hline \multicolumn{3}{|c|}{ + Weak production } & \multicolumn{4}{|c|}{$\begin{array}{l}+++ \text { Strong production } \\
\text { an with standard error }\end{array}$} & \multicolumn{2}{|c|}{ - No production } \\
\hline
\end{tabular}

\section{Mineral solubilization}

Out of eleven isolates tested for phosphate solubilization activity, ASR-19 showed highest zone of solublization (18.00 $\pm 1.15 \mathrm{~mm})$, followed by, MNR-10 (13.66 \pm $0.33 \mathrm{~mm})$, KTR-1 (13.66 $\pm 0.33 \mathrm{~mm})$, GR-5 (10.33 $\pm 0.88 \mathrm{~mm})$, GNR-8 (8.33 \pm $0.88 \mathrm{~mm})$. Among eleven isolates, GNR-7 showed highest potassium solubilization zone (14.66 $\pm 0.88 \mathrm{~mm})$, followed by MR-11 $(5.33 \pm 0.88 \mathrm{~mm})$,
MNR-10 (13.00 $\pm 0.57 \mathrm{~mm})$, RR-1 $(10.33 \pm 0.88 \mathrm{~mm})$, RR-3 $(7.33 \pm 0.88 \mathrm{~mm})$. Out of eleven isolates, GR-5 showed maximum zinc solubilization activity with solubilization zone $(15.00 \pm 1.73 \mathrm{~mm})$, followed by GNR $-7(14.66 \pm 0.88 \mathrm{~mm})$, WR-14 (13.00 $\pm 1.15 \mathrm{~mm})$, MNR-10 (10.33 $\pm 0.88 \mathrm{~mm})$ and RR-1 (8.33 \pm $0.33 \mathrm{~mm})$. Eleven isolates were tested for production of indole acetic acid. The data revealed that RR-1 showed highest IAA production $(18.70 \pm 0.14 \mu \mathrm{g} \mathrm{ml}-1)$, 
followed by MR-11 (12.48 $\left.\pm 0.25 \mu \mathrm{g} \mathrm{ml}^{-1}\right)$, MNR-10 (10.36 $\left.\pm 1.15 \mu \mathrm{g} \mathrm{ml} \mathrm{l}^{-1}\right), \mathrm{GR}-5$ $\left(10.21 \pm 0.00 \mu \mathrm{g} \mathrm{ml}^{-1}\right)$, ASR-19 $\left(9.55 \pm 1.44 \mu \mathrm{g} \mathrm{ml}^{-1}\right)$, YR-21 $(8.50 \pm 0.25 \mu \mathrm{g} \mathrm{ml}$ 1).

\section{Biocontrol activity of rhizobial isolates}

Among eleven isolates only one isolate showed weak (++) HCN production (WR14). Antifungal activity of eleven isolates was checked against Rhizoctonia solani and under in vitro conditions using PDA media. One isolate (WR-14) showed highest inhibition zone (13 mm) with Rhizoctonia solani.

\section{ACC deaminase activity}

All the Rhizobium isolates were screened for ACC deaminase based on the enrichment method under drought stress conditions $(-0.30 \mathrm{Mpa})$ where ACC was used as the sole nitrogen source. Among eleven isolates, five isolates (45\%) positive for ACC deaminase production by utilization of ACC the sole nitrogen source. Among five isolates, three isolates were moderate (t+) in ACCd production (RR-1, WR-14), two isolates were weak (+) for ACCd production (GR5, GNR-8, ASR-17). [18] reported similar results i.e fifty Mesorhizobium isolates were obtained from nodules of chickpea plants on yeast extract mannitol agar medium. Mesorhizobium isolates were screened for ACC utilization and growth at different salt concentrations in YEMA medium. They had also observed that Mesorhizobium strains having ACC utilization ability caused an increase in the nodule number, nodule weight and shoot dry weight after plant growth for 50 and 80 days, both with and without $\mathrm{NaCl}$

\section{Exo polysaccharide production}

All the Rhizobium isolates were screened for exo polysaccharide production based on the enrichment method under drought stress conditions $(-0.30 \mathrm{Mpa})$. Among the eleven isolates, six isolates (54\%) were positive for EPS production. Among six, two isolates showed moderate (++) EPS production (RR-1, WR-14) and four isolates showed weak (+) EPS production (RR-3, GR-5, GNR-8, ASR17). [19] reported greater EPS production with greater acid tolerance for a nonisogenic set of strains of Rhizobium. Rhizobium spp. YAS34 was selected from the indigenous sunflower tap root micro flora for its ability to produce large amounts of gel-forming exo polysaccharides that play an active role in plant development in a non-symbiotic context [20], whereas EPS production by Rhizobium populations is usually known to be crucial for establishment of successful symbiosis with legumes.

\section{Temperature tolerance of rhizobial isolates}

Screening of rhizobial isolates for temperature tolerance. All the twenty one rhizobial isolates were tested for temperature tolerance at $30,35,40,45$ and $50^{\circ} \mathrm{C}$ temperature [Table-3] \& [Fig-1]. Almost all the rhizobial isolates showed considerable growth at 30 and $35^{\circ} \mathrm{C}$ while at $40{ }^{\circ} \mathrm{C}$. Only one isolate showed tolerance to temperature from $20^{\circ} \mathrm{C}-50^{\circ} \mathrm{C}$ (YR-21), three isolates were showed tolerance to temperature from $20^{\circ} \mathrm{C}-45^{\circ} \mathrm{C}$ (RR-1, GR-5, GNR-8), one isolate was showed tolerance to temperature from $30^{\circ} \mathrm{C}-45^{\circ} \mathrm{C}$ (MR-11), only one isolate were showed tolerance to temperature from $30^{\circ} \mathrm{C}-40^{\circ} \mathrm{C}$ (ASR-17). High tolerance to heat shock is common in in chickpea rhizobia and other species also [21], [22]. [23] obtained several strains of Rhizobium japonicum tolerant up to $40^{\circ} \mathrm{C}$. [24] studied growth of Rhizobium was at different temperatures by incubating bacterial cultures in YEM agar at $32^{\circ} \mathrm{C}, 34^{\circ} \mathrm{C}, 36^{\circ} \mathrm{C}, 38^{\circ} \mathrm{C}$ and $40^{\circ} \mathrm{C}$. [25] conducted greenhouse experiment at $28^{\circ} \mathrm{C}$ and $38^{\circ} \mathrm{C}$ to study the nitrogen fixing capacity of the soybean isolates showed that ten isolates had a symbiotic index of $80 \%$ effectiveness or greater compared to nitrogen fertilizer treatments at $28^{\circ} \mathrm{C}$. Some thermo tolerant isolates showed good nitrogen fixing performance at $38^{\circ} \mathrm{C}$. A large number of rhizobia from root nodules of Prosopis juliflora were screened for hightemperature tolerance by [26].

\section{Drought tolerance of rhizobial isolates}

The drought tolerance of all the twenty one rhizobial isolates was tested in YEM broth supplemented with different concentrations of PEG 6000 [Table-4] \& [Fig-2].
Table-3 Growth in terms of absorbance at $600 \mathrm{~nm}$ of rhizobial isolates at different temperatures

\begin{tabular}{|c|c|c|c|c|c|}
\hline \multirow{2}{*}{ Isolates } & \multicolumn{5}{|c|}{ Temperature tolerance $\left(^{*}\right)$} \\
\cline { 2 - 6 } & $20^{\circ} \mathrm{C}$ & $30^{\circ} \mathrm{C}$ & $40^{\circ} \mathrm{C}$ & $45^{\circ} \mathrm{C}$ & $50^{\circ} \mathrm{C}$ \\
\hline RR 1 & 0.20 & 0.89 & 0.09 & 0.100 & 0 \\
\hline RR 3 & 0.00 & 0.92 & 0.00 & 0.000 & 0 \\
\hline GR 5 & 0.20 & 0.80 & 0.45 & 0.207 & 0 \\
\hline GNR 7 & 0.00 & 0.80 & 0.00 & 0.000 & 0 \\
\hline GNR 8 & 0.02 & 0.95 & 0.10 & 0.090 & 0 \\
\hline MR 10 & 0.02 & 0.89 & 0.00 & 0.000 & 0 \\
\hline MR 11 & 0.00 & 0.90 & 0.22 & 0.180 & 0 \\
\hline WR 14 & 0.00 & 1.00 & 1.00 & 0.000 & 0 \\
\hline ASR 17 & 0.00 & 0.89 & 0.25 & 0.000 & 0 \\
\hline ASR 19 & 0.00 & 1.00 & 0.00 & 0.000 & 0 \\
\hline YR 21 & 0.12 & 0.98 & 0.20 & 0.137 & 0.02 \\
\hline CD & 0.019 & 0.045 & 0.125 & 0.013 & \\
\hline SE(m) & 0.006 & 0.015 & 0.042 & 0.004 & \\
\hline & & & & & \\
\hline
\end{tabular}

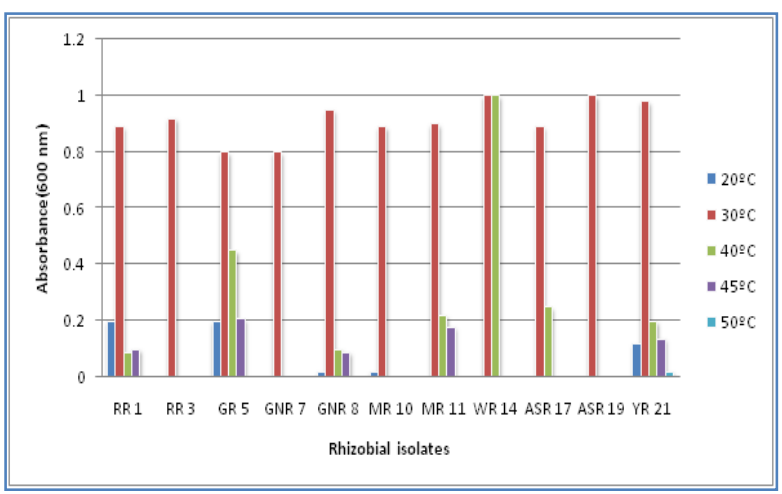

Fig- 1 Temperature tolerance by rhizobial isolates

The results of drought tolerance ability of Rhizobium isolates revealed that, two isolates showed tolerance to water potential from - $0.05 \mathrm{Mpa}$ to- $0.15 \mathrm{Mpa}$ (RR-1, RR-3), three isolates were showed tolerance to water potential from - $0.05 \mathrm{Mpa}$ to$0.30 \mathrm{Mpa}$ (GNR-8, ASR-19, YR-21), only one isolate showed tolerance to water potential at $-0.05 \mathrm{Mpa}$ (GNR-7). The growth and persistence of rhizobia and bradyrhizobia in soils are negatively impacted by drought conditions [27]. [28] studied 30 isolates using YEM broth supplemented with PEG and he reported that the concentration of PEG increased, the growth of rhizobial isolates was found to decrease. [29] grouped Sinorhizobium spp. in two clusters: sensitive and tolerant based on their growth rate in YEM broth containing different concentrations of PEG. [30] reported that Rhizobium spp. NBRI2505 sesbania, when subjected to drought stress, tolerated YEB containing 45\% polyethylene glycol 6000 for up to 5 days of incubation at $30^{\circ} \mathrm{C}$.

Table-4 Growth in terms of absorbance at $600 \mathrm{~nm}$ of rhizobial isolates supplemented with different concentration of polyethylene glycol (PEG 6000)

\begin{tabular}{|c|c|c|c|c|}
\hline \multirow{2}{*}{ Isolates } & \multicolumn{4}{|c|}{ Drought stress $\left(^{*}\right)$} \\
\cline { 2 - 5 } & $-0.05 \mathrm{Mpa}$ & $-0.15 \mathrm{Mpa}$ & $-0.30 \mathrm{Mpa}$ & $-0.73 \mathrm{Mpa}$ \\
\hline RR 1 & 0.20 & 0.02 & 0.00 & 0.00 \\
\hline RR 3 & 0.26 & 0.03 & 0.00 & 0.00 \\
\hline GR 5 & 0.00 & 0.00 & 0.00 & 0.00 \\
\hline GNR 7 & 0.35 & 0.00 & 0.00 & 0.00 \\
\hline GNR 8 & 0.28 & 0.02 & 0.01 & 0.00 \\
\hline MR 10 & 0.00 & 0.00 & 0.00 & 0.00 \\
\hline MR 11 & 0.00 & 0.00 & 0.00 & 0.00 \\
\hline WR 14 & 0.00 & 0.00 & 0.00 & 0.00 \\
\hline ASR 17 & 0.00 & 0.00 & 0.00 & 0.00 \\
\hline ASR 19 & 0.38 & 0.30 & 0.01 & 0.00 \\
\hline YR 21 & 0.40 & 0.20 & 0.04 & 0.00 \\
\hline CD & 0.033 & 0.009 & 0.003 & \\
\hline SE(m) & 0.011 & 0.003 & 0.001 & \\
\hline
\end{tabular}




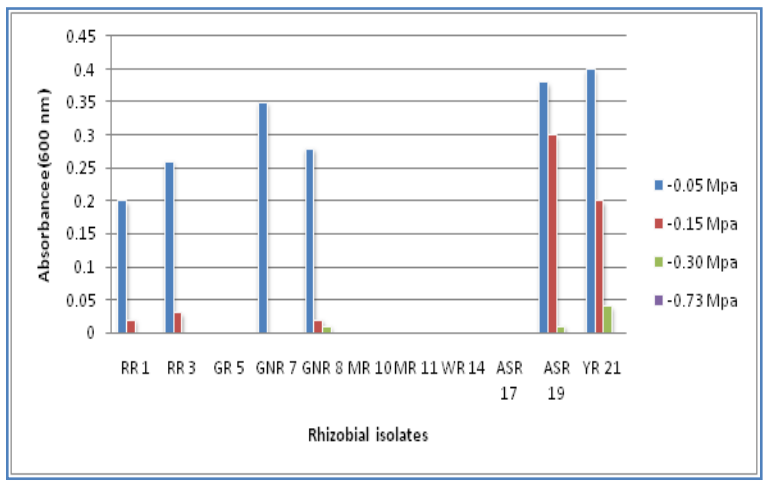

Fig- 2 Drought tolerance by rhizobial isolates

For plant growth promoting properties, Rhizobium isolate RR-1 showed good nodulation and moderate P-solubilization in addition to highest IAA production, ACC deaminase \& EPS production and considerable other PGP properties. MR10 showed efficient nodulation, moderate $p$-solubilization, $k$ - solubilization, zn solubilization and considerable other PGP properties. WR-14 showed efficient nodulation, Zn-solubilization and ACC deaminase, EPS production. GR-5 showed highest Zn-solubilization and moderate in ACC deaminase \& EPS production.

For biocontrol properties such as HCN production, Siderophore production and antifungal activity with Rhizoctonia solani, the Rhizobium isoalate WR-14 showed moderate HCN production and antifungal activity with Rhizoctonia solani

For plant growth promoting properties and biocontrol, Rhizobium isolate WR-14 was efficient as it showed efficient nodulation, Zn-solubilization and ACC deaminase \& EPS production and moderate biocontrol activity, HCN production and antifungal activity with Rhizoctonia solani.

The Rhizobium isoalate MR-10 found efficient in terms of plant growth promoting properties and abiotic stress as it exhibited efficient nodulation, moderate P. solubilization, K-solubilization, Zn-solubilization and other PGP properties. It was able to tolerate temperature stress and drought stress $(-0.15 \mathrm{MPa}-0.3 \mathrm{MPa})$.

None of the isolates had shown positive for PGP properties, biocontrol activity and tolerance to abiotic stress conditions. However, Rhizobium isolates MR-10 and WR-14 mentioned earlier could be a used in combination to meet the requirement of PGPP, Biocontrol and Abiotic stress conditions. Hence these isolates might be potential as bioinoculants in different arid climatic regions of Telangana.

\section{Conclusion}

It can be summarized that PGPR isolates from the present study, Rhizobium isolates MR-10 and WR-14 mentioned earlier could be a used in combination to meet the requirement of PGPP, Biocontrol and Abiotic stress conditions. have good potential to be used as bioinoculants with further confirmation under in vivo conditions.

Application of research: The scope of the present research work as on isolation, screening and identification of PGP rhizobia for stress tolerance under in vitro conditions. The different rhizobia were studied for their stress tolerance properties. It is intended that the potential PGPR isolates would be studied under in vivo conditions with suitable crops for establishing their use as bioinoculants.

\section{Research Category: Stress tolerant rhizobia}

\section{Abbreviations:}

HCN: Hydrogencyanic acid

PGP: plant growth promoting properties

ACC: 1-amino cyclopropane cyclohexane

YEMA: yeast extract mannitol agar

EPS: exo polysaccharides

ASR: Adilabad soybean rhizobium

RR: Rangareddy Rhizobium

YR: Yadagirigutta Rhizobium
Acknowledgement / Funding: The authors are thankful to Professor Jayashankar Telangana State Agricultural University, Rajendranagar, Hyderabad, 500030, Telangana. Author acknowledge the financial support extended by the University Grants Commission for National fellowship year 2016-17.

\section{*Chairperson of research: Professor Dr Subhash Reddy}

University: Professor Jayashankar Telangana State Agricultural University, Rajendranagar, Hyderabad, 500030, Telangana.

Research project name or number: PhD Thesis

\section{Author Contributions: All author equally contributed}

Author statement: All authors read, reviewed, agree and approved the final manuscript

\section{Conflict of Interest: None declared}

Ethical approval: This article does not contain any studies with human participants or animals performed by any of the authors.

\section{References}

[1] Lupwayi N.Z., Clayton G.W., Hanson K.G., Rice W.A. and Biederbeck V.O. (2004) Canadian Journal of Plant Science, 84,37-45.

[2] Biswas J.C., Ladha J.K., Dazzo F.B., Yanni Y.G. and Rolfe B.G. (2000) Agronomy Journal, 92,880-886.

[3] Chaintreuil C., Giraud E., Prin Y., Lorquin J., Ba A. and Gillis M. (2000) Appl Environmental Microbiology, 66, 5437-5447.

[4] Peoples M.B., Herridge D.F. and Ladha J.K. (1995) Plant Soil, 174, 3-28.

[5] Harb A., Krishnan A., Ambavaram M.M.R. and Pereira A. (2010) Plant Physiology, 154 (3), 1254-1271.

[6] Wei G.H., Yang X.Y., Zhang Z.X., Yang Y.Z. and Lindstrom K. (2008) Pedosphere, 18,102-112.

[7] Kloepper J.W., Ryu C.M. and Zhang S.A. (2004) Phytopathology, 94, 12591266.

[8] Yang L., Zhai L., Wang R., Zhao R., Zhang X., Chen C., Cao Y., Cao Y., Xu T., Ge Y., Zhao J and Cheng C. (2015) International Journal of Systematic and Evolutionary Microbiology, 65, 4533-4538.

[9] Pikovskaya R.I. (1948) Microbiologia, 17, 362-370.

[10] Prajapati M.C and Modi H.A. (2012) Life sciences Leaflets, 5, 71-75.

[11] Saravanan V.S., Subramoniam S.R and Raj S.A. (2003) Brazilian Journal of Microbiology, 34, 121-125.

[12] Gorden A.S and Weber R.P. (1951) Plant Physiology, 26, 192-195.

[13] Ali S.Z., Sandhya V. and Rao L.V. (2013) Annals of Microbiology, 5, 1-10.

[14] Jacobson C.B., Pasternak J.J. and Glick B.R. (1994) Canadian Journal of Microbiology, 40, 1019-25.

[15] Schwyn B. and Neilands J.B. (1987) Analytical Biochemistry, 160, 47-56.

[16] Skidmore A.M. and Dickinson C.H. (1976) Transactions and Journal of the British Ceramic Society, 66, 57-74.

[17] Sandhya V., Ali S.Z., Grover M., Reddy G. and Bandi V. (2009) Journal of Plant Interactions,6,1-14.

[18] Deepika Chaudhary and Satyavir Singh Sindhu (2017) Legume Research, 40(1), 80-86.

[19] Cunningham D. and Munns D. N. (1984) Soil Science, 48, 1273-1276.

[20] Requena N., Perez-Solis E., Azcon-Aguilar C., Jeffries P. and Barea J.M. (2001) Applied and Environmental Microbiology, 67, 495-498.

[21] Kulkarni S. and Nautiyal C. S. (2000) Current Microbiology, 40, 221-226.

[22] Rodriguez H., Fraga R., Gonzalez T. and Bashan Y. (2006) Plant soil, 287, 15-21.

[23] Karanja N. K. and Wood M. (1988) Plant Soil, 112, 15-22.

[24] Singh R.P., Bauddh K., Sainger M., Singh J.S and Jaiwal P.K. (2011) Nitrogen use efficiency in higher plants under drought, high temperature, salinity and heavy metal contaminations, in Nitrogen Use Efficiency in 
Plants, eds Jain V., Kumar A.P., editors. New Delhi: New India Publishing Agency, 99 -123.

[25] Rahmani H.A., Saleh rastin N., Khavazi K., Asgharzaden A., Fewer D., Kiani S. and Lindstrom K. (2009) World J. Microbiol. Biotechnol., 25, 591600.

[26] Kulkarni S. and Nautiyal C.S. (1999) Journal General and Applied Microbiology, 45, 213-220.

[27] Cytryn E.J., Sangurdekar D.P., Streeter J.G., Franck W.L., Chang W.S., Stacey G., Emerich D.W., Joshi T., Xu, D. and Sadowsky M.J. (2007) Journal of Bacteriology, 189, 6751-6762.

[28] Uma C., Sivagurunathan P. and Sangeetha D. (2013) International Journal of Current Microbiology and Applied Sciences, 2(5), 228-232.

[29] Abolhasani M., Lakzian A., Tajabadipour A. and Haghnia G. (2010) Australian Journal of Basic and Applied Sciences, 4(5), 882-886.

[30] Rehman A. and Nautiyal C.S. (2002) Effect of drought on the growth and survival of the stress-tolerant bacterium Rhizobium spp. NBR/2505 sesbania and its drought-sensitive transposon Tn5 mutant, Springer-Verlag New York LLC., 45(5), 368-377. 